\title{
Makeup Therapy for Scars
}

Joëlle Nonni

\section{Contents}

49.1 Definition - 436

49.2 Characteristics -436

49.3 The Benefits of Medical Makeup - 436

49.3.1 Psychological Impact - 436

49.3.2 Social Impact -436

49.4 Medical Makeup - 436

49.4.1 Step-by-Step Process -436

49.4.2 Using Color Correction Is the Best Solution to This Issue - 437

49.4.3 Complementary Colors - 437

49.4.4 The Value of Colors - 437

49.4.5 Compact Foundation Creams - 438

49.4.6 Fluid Foundation Correctors - 439

49.5 Medical Makeup Classes - 440

References - 440 
Medical makeup is a solution to hide scars and burns on the face as well as body, to both men and women. The objective is to reduce the psychological impact and to improve the patient's self-image.

Various studies have highlighted the positive effect of medical makeup on the patient's quality of life. With medical makeup, patient's self-confidence gradually comes back.

\subsection{Definition}

The priorities for medical makeup are different from those for cosmetic makeup, which is primarily concerned with fashion and trends. With medical makeup, first and foremost, camouflage solutions must be found that do not risk aggravating skin lesions, the objective being to reduce the psychological impact and to improve the patient's self-image. The aim is therefore not to create the "most beautiful makeup" but to find corrective products that are compatible with medical prescriptions, skin sensitivity, the expectations of the patient, and their ability to put on the makeup. Medical makeup is offered to both men and women and helps hide lesions on the face as well as the body.

\subsection{Characteristics}

- Makeup referred to as "medical" is formulated to guarantee complete safety even for damaged skin [1].

- Products are hypoallergenic and non-comedogenic and must contain a high sun-protection factor.

- The quality of textures is important to make it easier to apply the makeup and also to achieve a natural result.

- It is essential that the makeup be long lasting and resistant to water and sweat so that it lasts all day long. That being the case, the description of the product on the packaging should be checked to make sure they have all these qualities.

- The anhydrous forms, and stick and compact types are resistant because their outer oily phase is less miscible with water. For the other formulas, the addition of polymer increases the adhesion of the product to the skin and thus limits its migration into the water.

- By using makeup products that are resistant to water and perspiration, the makeup hold may be greater than 10 hours.

- However, one last important point should be emphasized: the makeup must be easy to remove so as not to cause a secondary irritation.

\subsection{The Benefits of Medical Makeup}

Various studies have highlighted the positive effects of medical makeup on the patient's quality of life, particularly in the case of treatment for scars.

\subsubsection{Psychological Impact}

By learning how to conceal their skin imperfections, patients:

- Find it easier to look at themselves in the mirror

- Regain a more realistic body image

- Enjoy taking care of themselves again

- Grow in self-confidence

The patient's self-esteem is boosted and they find it easier to look to the future.

\subsubsection{Social Impact}

After having concealed highly visible lesions, patients:

- Are less likely to notice the sometimes "intrusive" looks from other people

- Find other people look at them more approvingly again

- Maintain or return to social activities

- Are able to continue working if they wish to do so

Their relationship with others is improved, thus avoiding or putting an end to their sense of isolation.

\subsection{Medical Makeup}

\subsubsection{Step-by-Step Process}

\subsubsection{Evaluation of Needs}

The first step is to evaluate the needs and expectations of patients.

What products does the doctor recommend: emollient, sun protection, etc.?

- What does the patient want to conceal?

- Does the patient want a highly corrective or a lighter type of makeup?

- Does the patient usually apply makeup?

- Always remember to adapt the advice according to sex, age, habits, and preferences.

- And to give advice that the patient can easily replicate.

\subsubsection{Makeup Base}

Applying an emollient cream is essential for correcting a skin imperfection. Skin must be moisturized and supple to be able to spread the foundation easily. If the skin is not moisturized, the pigments contained in the makeup 
will stick to raised areas of the skin, the correction will not be even, and the makeup will not last for the entire day. If sun protection is required, apply this after the emollient cream, using it as the makeup base [2]

\subsubsection{Color Correction}

Thick makeup often gives the impression of a mask effect and sometimes gives burn patients' faces a frozen look. The makeup must therefore be lighter so that the patient does not feel their personality has been stripped away after having it applied [3].

\subsubsection{Using Color Correction Is the Best Solution to This Issue}

By experimenting with color, we can reduce the intensity of imperfections, which means less foundation needs to be applied therefore obtaining a more natural result.

\subsubsection{Complementary Colors}

The principle is to superimpose two complementary colors in order to neutralize them.

As we can see from the chromatic circle (• Fig. 49.1):

- Green is the opposite color to red

- Yellow is the opposite color to purplish blue

- Coral is the opposite color to dark blue

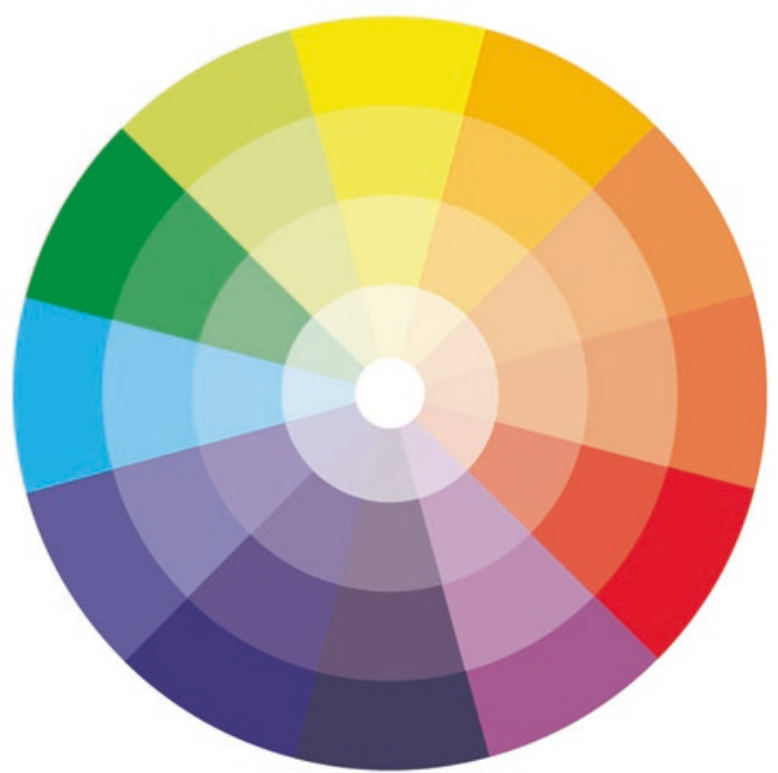

- Fig. 49.1 Complementary color circle. Source: Eau Thermale Avène. (C) All rights reserved

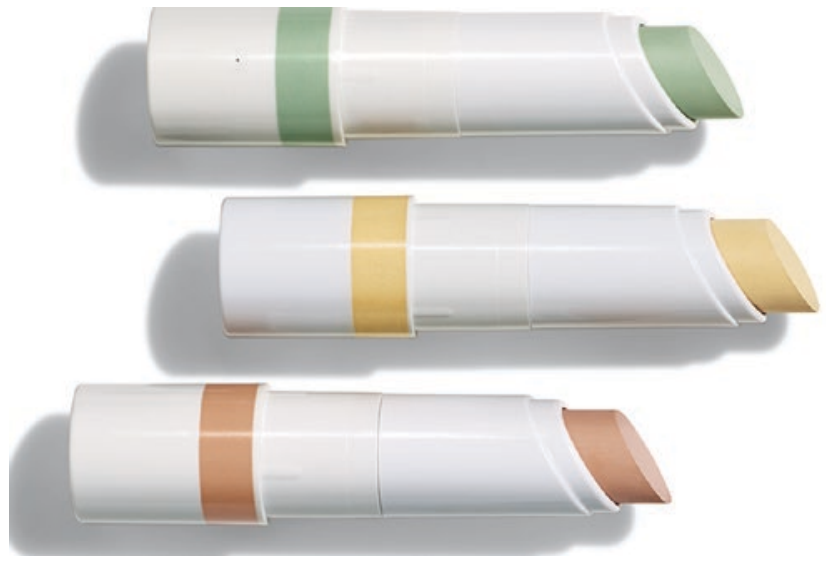

- Fig. 49.2 Corrector sticks. Source: Eau Thermale Avène. (C) All rights reserved

Therefore:

- A green corrector neutralizes imperfections that are predominantly red: inflammatory scars, rosacea, psoriasis, etc.

- A yellow corrector neutralizes imperfections that are predominantly purplish: ecchymosis, angioma, bluetoned dark circles, varicose veins, etc.

- A coral corrector neutralizes imperfections that are predominantly dark-blue: tattoos, nevus of Ota, etc. (• Fig. 49.2)

After having applied a corrector, the imperfection becomes slightly grey; therefore, it is not necessary to apply as much foundation.

\subsubsection{The Value of Colors}

The light amplitude of a color is known as its "value," from the lightest to the darkest; adding white or black to a color is all that is required to change its intensity. For example, with orange, as we can see from the chromatic circle, its dark value is brown and its light value is beige [4] (- Fig. 49.3).

In practice, if we want to correct a brown imperfection, it is necessary to apply an orange-ish shade to obtain a bright, light beige color, before applying foundation.

Therefore:

- A coral corrector neutralizes imperfections that are predominantly brown: hyperpigmented scars, melasma, brown-toned dark circles, lentigos, etc.

After having corrected the colored lesions using the complementary colors or the value of colors, we simply need to cover this with a little foundation to even out the complexion. 


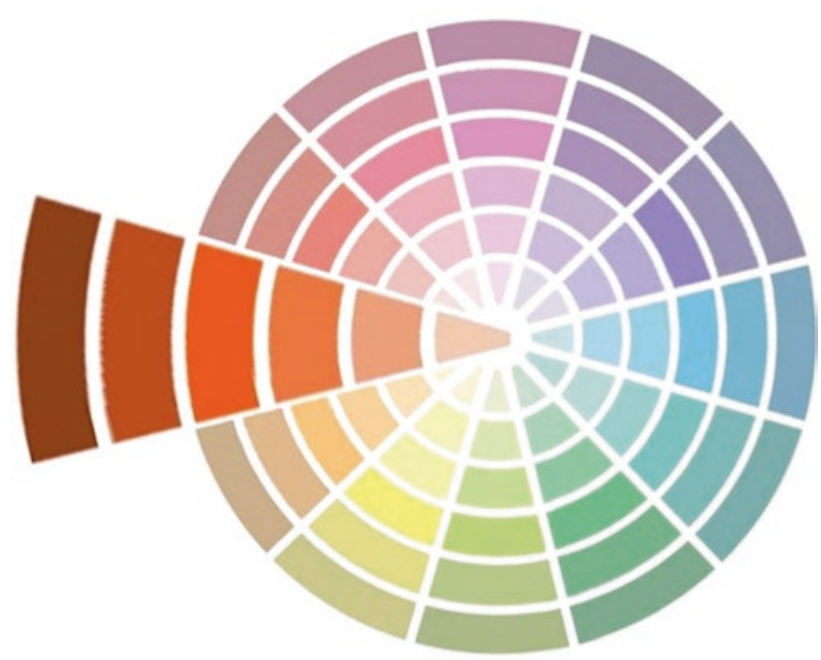

- Fig. 49.3 Color value circle. Source: Eau Thermale Avène. (C) All rights reserved

\subsubsection{Corrective Foundations}

Corrective foundations offer several advantages for medical makeup.

- Their high pigment concentration allows for correction using less product.

- Their excellent resistance means that there is no need to reapply the product during the day.

- Their resistance to water and sweat means they can be used in any situation, both on the face and body.

- They have a high sun protection factor.

There are two types of corrective foundations:

- Fluid for mild imperfections

- Compact for severe imperfections

\subsubsection{Compact Foundation Creams}

These are the most suitable for concealing severe imperfections and particularly for a long-lasting effect and a water, sweat resistance finish.

- For post-surgery patients: it is better to use a "comfort" texture with a supple formula that is easily applied, even on the most sensitive skin.

- For remote post-surgery patients: we select a "comfort" texture for the face and a "matt-finish" texture for the body as there is no transfer and excellent resistance [5] (• Figs. 49.4 and 49.5).
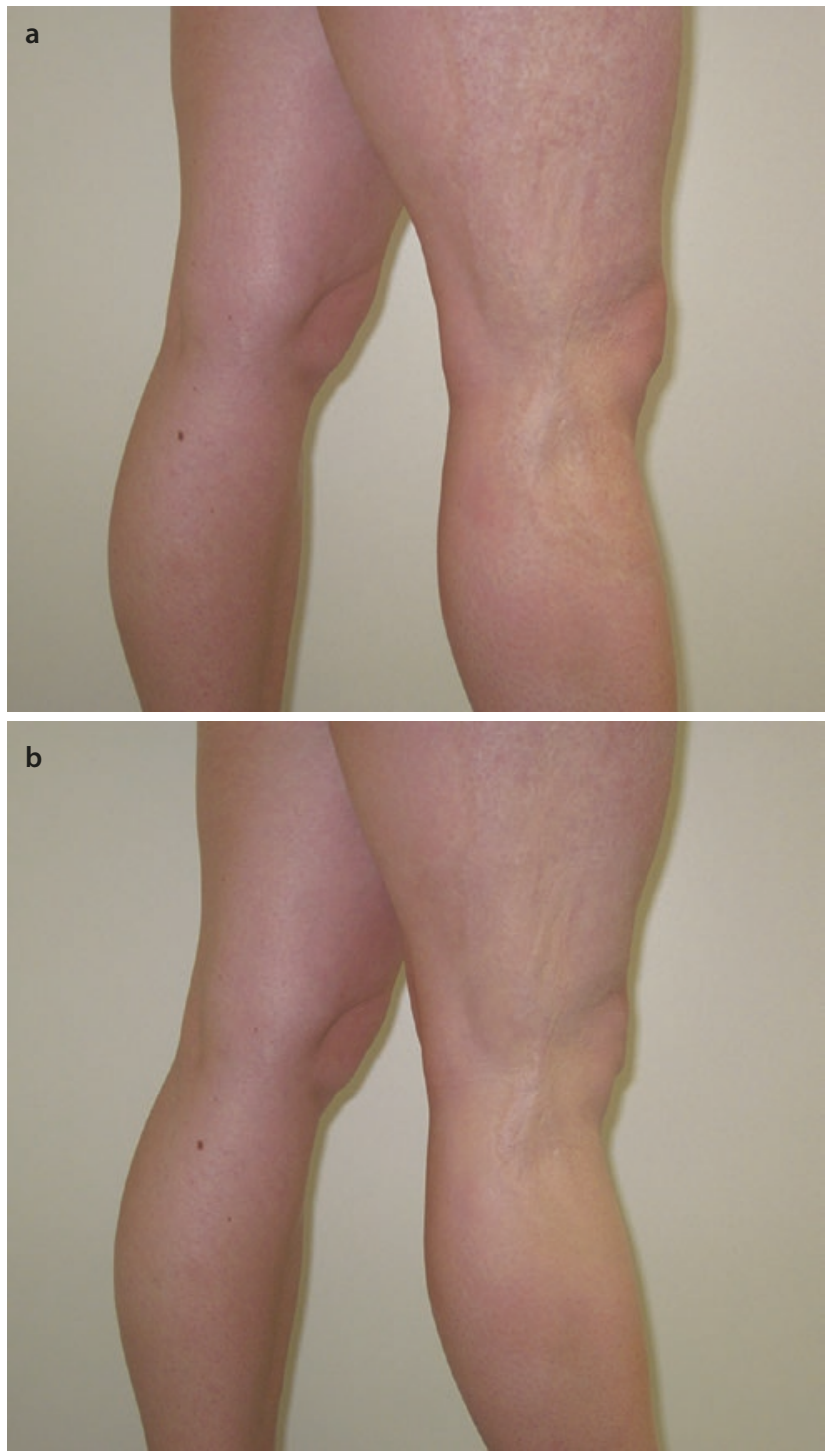

- Fig. 49.4 Legs before (a) after (b) make up Source: Eau Thermale Avène. (C) All rights reserved

It is better to apply these products with a sponge and therefore the finish can be adapted depending on the intensity of the imperfection.

- For a high-coverage result or after using a color corrector, apply by dabbing.

- For a transparent result, apply by smoothing.

Do not forget to regularly clean the sponge with soap and water, or simply by washing it in the washing machine. 

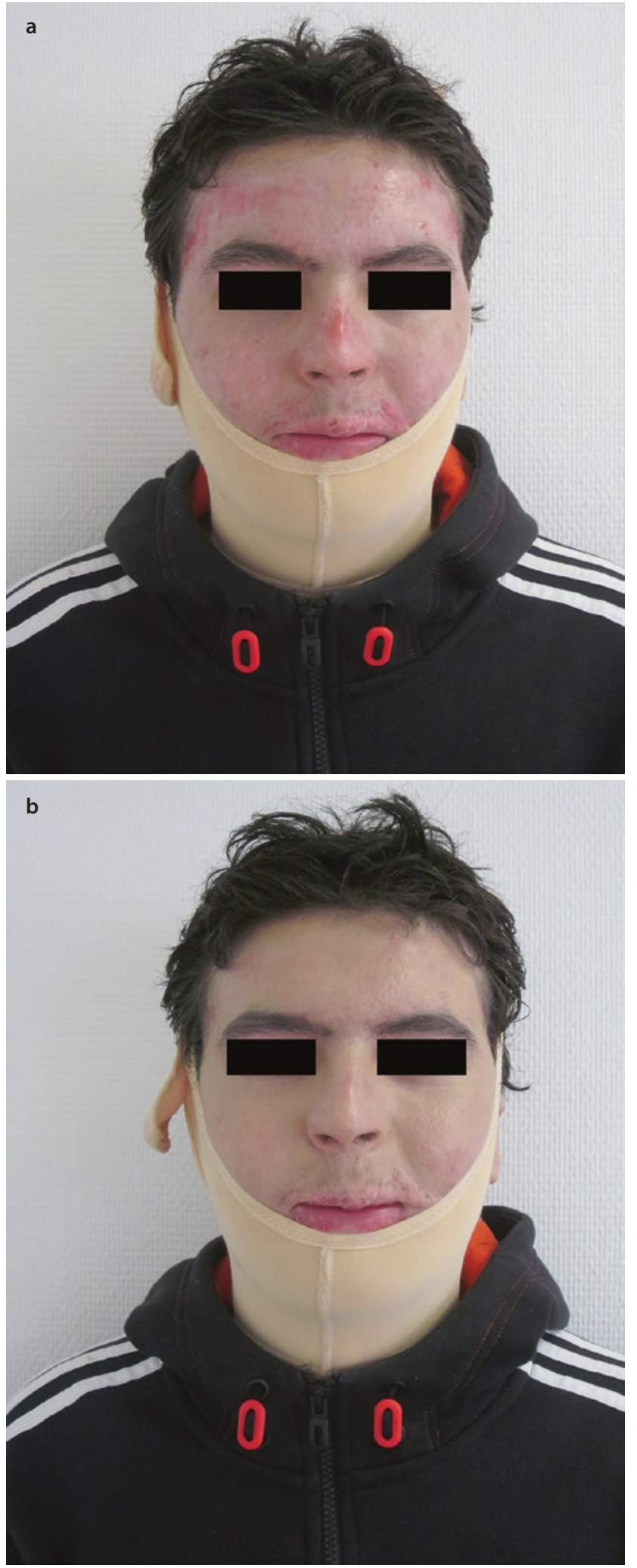

- Fig. 49.5 Face make up: before (a) and after (b). Source Eau Thermale Avène. (C) All rights reserved

\subsubsection{Fluid Foundation Correctors}

These are more suitable for mild to moderate imperfections and as they have a lower pigment concentration, they are ideal for scaly skin. They can be applied using the tips of the fingers, but if the skin is very dry or scaly, a sponge is more effective to "blur" the scales. As for foundation brushes, they are chosen for a more transparent finish and for men who really like this method of application.

\subsubsection{How to Decide on a Shade of Foundation}

People often select the color of their foundation according to the color on the inside of their wrist, but this body area is quite fair and therefore this rarely achieves a natural result. The most effective method is to test the product on the jawline to check that there is no demarcation between the face and neck. For the body, test the product next to the imperfection that you are going to apply makeup to. In case of hyperpigmentation, opt for a shade that is slightly darker than the skin tone; this will help with correction.

\section{Powder}

This is essential to set the makeup and to ensure longlasting hold. Opt for a powder suited to the skin tone and apply it with a large brush for a more natural effect. When scars are very raised, finish by applying the powder in the opposite direction to get rid of excess product so that the makeup is less visible. If skin is very scaly, it is better to avoid applying powder as it accentuates the appearance of scales.

\section{Corrector Pencils}

\section{Eyebrows}

Eyebrow corrector pencils are extremely useful for concealing localized scars around the eyebrows or to completely redefine and rebalance the eye area. The eyebrows are so important in makeup that it is said they act as a "frame for the eyes."

\section{Lips}

In case of scarring around the mouth, a lip pencil is generally applied after having concealed the scar with foundation and a little bit of powder. The lip pencil is therefore used to define the contours of the mouth [6]. In the case of cheilitis, you can suggest using a lip balm before applying lipstick, which can be used instead of lip gloss to treat dry lips at the same time. 


\section{Ensure Makeup Lasts longer}

Spray a fine mist of thermal water $20 \mathrm{~cm}$ away from the makeup and leaving it to evaporate, this dries the makeup and makes it last longer. This is a very useful technique for body makeup, which is more subject to friction than the face.

\section{Makeup Removal}

An essential step! Most of the time, makeup remover is put on a cotton pad and rubbed against the skin with varying levels of force. If the pressure from the cotton pad is not strong enough, the makeup is not removed and if it is too strong, this could cause an irritation. The most suitable method is to remove makeup with just the tips of your fingers. The makeup remover must contain gentle surfactants, be fragrance-free, and in the form of a lotion or gel-like lotion so that it can be applied using gentle massage with the tips of the fingers. After having loosened the makeup and impurities, gently remove the rest with paper tissues before rinsing with a thermal water spray to achieve perfectly cleansed skin.

\section{In brief:}

1. Evaluation of needs: to evaluate the needs and expectations of patients

2. Makeup base: to prepare the skin before the makeup

3. Color correction: to neutralize the color imperfection

4. Corrective foundation: to unify the tone of the skin

5. Powder: to set the makeup

6. Corrector pencil: to correct scars or depigmentation on eyebrows and lips

7. Fine mist of thermal water: ensure makeup lasts longer

8. Makeup removal: to remove the makeup without creating irritation

\subsection{Medical Makeup Classes}

Because each patient needs personnel advice, it is important for them to learn how to hide their imperfections from medical make-up specialists or nurses similarly trained. Usually, these classes or workshops are in hydrotherapy centers specializing (in skin disorders), functional rehabilitation centers, or hospitals.

At first, patients can have individual advice, and they can also join a workshop with other patients to learn how to do it by themselves. This last solution is the best way to become autonomous and generally men should opt for this more than women, because usually men do not use makeup and they need to be more careful in applying it.

\section{Take-Home Message \\ Medical makeup can be applied to all imperfections, ranging from mild to severe. It can be applied to the face and body and should be offered to men as well as women. Various studies have highlighted the positive effects of medical makeup on the patient's quality of life [7]. It improves patients' personal relationships and daily activities and reduces esthetic prejudice [8].}

\section{References}

1. McMichael L. Skin camouflage. BMJ. 2012:d7921.

2. Grognard C. Tatouage et maquillage réparateur, 2008. p. 25.

3. Delebecque-Eginer C, Ferrere R, Nonni J, Segard C, Encyclopédie Médico-Chirurgicale, Maquillage: Technique de camouflage. Cosmestologie et dermatologie. 2000; 50-170-E-10.

4. Delamar P. Le maquillage artistique. Editions Vigot. 2002:8.

5. Nel-Omeyer M, Ambonati M, Mengeaud V, Taieb C, MerialKieny C, Intérêt du maquillage correcteur médical chez les grands brûlés : impact sur la qualité de vie , tolérance et acceptabilité cosmétique. J Plaies et cicatrisation. 2007;58: tome XII.

6. Mérial-Kieny C, Nonni J. Maquillage de correction médicale pour les peaux brûlées. J Plaies et cicatrisation. 2006;53, tome XI.

7. Holmes SA, Beattie PE, Fleming CJ. Cosmetic camouflage advice improves quality of life. $\mathrm{Br} \mathrm{J}$ Dermatol. 2002;147: 946-9.

8. Graham JA, Jouhar AJ. The importance of cosmetics in the psychological appearance. Int J Dermatol. 1983;22:153-6.

\footnotetext{
Open Access This chapter is licensed under the terms of the Creative Commons Attribution 4.0 International License (http://creativecommons. org/licenses/by/4.0/), which permits use, sharing, adaptation, distribution and reproduction in any medium or format, as long as you give appropriate credit to the original author(s) and the source, provide a link to the Creative Commons license and indicate if changes were made.

The images or other third party material in this chapter are included in the chapter's Creative Commons license, unless indicated otherwise in a credit line to the material. If material is not included in the chapter's Creative Commons license and your intended use is not permitted by statutory regulation or exceeds the permitted use, you will need to obtain permission directly from the copyright holder.
} 